\title{
The Promotion of Physical Literacy through an "Active Classroom" Environment: A Case Study of the Manchester United Enterprise Foundation
}

\author{
Jonathan Styles*, Robert Martin \\ Alliance Manchester Business School, University of Manchester, Manchester, UK \\ Email: ${ }^{\star} J o n a t h a n . s t y l e s @ m a n c h e s t e r . a c . u k$, robert.martin@postgrad.mbs.ac.uk
}

How to cite this paper: Styles, J., \& Martin, R. (2017). The Promotion of Physical Literacy through an "Active Classroom" Environment: A Case Study of the Manchester United Enterprise Foundation. $A d$ vances in Physical Education, 7, 168-180. https://doi.org/10.4236/ape.2017.72015

Received: January 13, 2017

Accepted: May 19, 2017

Published: May 22, 2017

Copyright (๑) 2017 by authors and Scientific Research Publishing Inc. This work is licensed under the Creative Commons Attribution International License (CC BY 4.0).

http://creativecommons.org/licenses/by/4.0/ (c) (i) Open Access

\begin{abstract}
Most people think football clubs such as Manchester United as providers of sports entertainment; however, the workings of English Premier League Football Clubs goes much wider than playing football and developing world class football players. Many clubs now recognise that their Brand identity can provide them with additional revenue opportunities, such as the creation and delivery of educational programmes. Sports science is one obvious area where football clubs, such as "Manchester United", have become recognised as world class developers of elite athletes through the implementation of their specialist training and coaching techniques. Many of these training techniques are now being developed into programmes e.g. Move with Manchester United and are being delivered across the National Curriculum at both primary and secondary levels. Alongside the development of sports programmes, leading football league clubs have identified other educational areas namely Enterprise and Employability, as opportunities where they can add value through the enhancement of children's educational experience. In this paper we aim to provide an insight into how a leading premier league football club, namely Manchester United, has developed an educational programme which combines both Enterprise and Physical education through an "active classroom" environment. We aim to demonstrate that a leading football club can successfully develop and implement curricular based programme which develops both elements of Entrepreneurship and Fundamental Motor Skills (FMS). For this pilot study, 22, year 5 pupils aged 9 - 10 were put through a 9 week programme and were assessed against a range of 14 Fundamental Movement Skills comprising Balance, Hopping, Skipping, Jumping, Throw into a Hoop, Balance Bean Bag on Head, Throw and Catch, Bounce and Catch, Bowling, March in Ladders, Jump and Twist, Pass with inside of foot, Stand with one
\end{abstract}


foot on the ball, dribbling. Pupils were assessed on their ability to Master each of the 14 skills before and after the intervention of the programme. Results indicated that through the intervention of the programme, pupils showed a significant improvement in 6 out of the 14 fundamental movement skills. These results indicate that organisations, such as leading football clubs, can play a pivotal role in the development and delivery of the educational programmes such as that described in the case study. This could be of potential value to educational policy makers when deciding on how to best allocate resources into both primary and secondary education.

\section{Keywords}

Active Classrooms, Fundamental Motor Skills, Manchester United

Foundation, Physical Activity

\section{Introduction}

According to Kremers et al. (2006), physical activity is a complex health related behaviour which consists of a number of different activities (e.g. walking, cycling, and jumping) which are routinely conducted as a natural part of daily life. Current evidence suggests that the provision of constant physically activity for children can promote both physical and mental health, thus reducing the prevalence of cardiovascular risk factors Andersen et al. (2006) and obesity Janssen et al. (2005).

Research carried out by (Janak et al., 2014; Kristjánsson et al., 2010; Basch, 2010; Fiscella \& Kitzman, 2009) has identified positive links between increases in physical activity, better health and academic success. Tomporowski et al. (2008) have also shown that a general improvement in brain function, performance of goal-oriented actions and adaption to new environments can be significantly increased in children through physical activities. Snelling et al. (2014) further states that this could play an important role in children's overall behaviour in class, ability to pay attention, to follow rules and process and apply learned information. Although evidence suggests that physical activity improves executive functioning of the brain, it remains unclear as to the type, duration, or intensity level of physical activity that results in such improvement in executive function Tomporowski et al. (2008). There is also strong evidence within the literature (Pellegrini \& Bohn, 2005; Boyle et al., 2003) to show that, the children who undertake physical activity to enhance the development of Key Motor Skills (KMS) (Shephard \& Lavallee, 1994) are not only more academically successful, but also have improved social skills, improved stress management skills and a greater strengthened emotional social support systems through positive selfesteem. However conversely, children who are disadvantaged by unhealthful behaviour have significantly lower scores on tests of academic achievement. Thus there is a continued need for the development and provision of physical activity participation both in and out of the school environment and this has 
been identified as major goals for the development of healthy people ( $\mathrm{Gu} \&$ Zhang, 2016).

Research on the provision of physical activity in schools has tended to focus on the role and delivery of physical education PE, with PE being identified as the main vehicle for the delivery of all physical activity within the school environment (Fairclough \& Stratton, 2005; Fairclough et al., 2002; Gard \& Wright, 2001; WHO, 1998). Organisations and health professionals such as the British Heart Foundation have further agreed that $\mathrm{PE}$ is an ideal medium for the provision of vigorous activity with targets of two-hours-a-week being set for children. However according to Davidson (2007), whilst many schools offer two hours of PE within their curriculum, the actual amount of physical activity undertaken by children within the lessons can be considerably less. There may be many contributing factors which can be attributed to this lack of provision, which in term could be driven by a lack of: finances, or resources such as appropriately trained educators.

Other scholarly research in the field has looked at the model of the "active school" approach (Davidson, 2007), whereby a school should commit to the "whole school approach" of physical activities. This is done through a variety of different strategies which focuses the development of the culture and the policy of the school through health-and-activity driven activities which are centred on the child (Fox et al., 2004; Cale, 1997). Cale (1997) goes on to suggest that there are a number of ways of categorizing the promoting physical activity, as part of a "whole school approach" which he states are:

- Policy;

- The curriculum;

- The informal curriculum;

- Ethos;

- Community links;

- The environment;

- Care and support.

Another delivery mode for the provision of physical activity that has attracted attention within the literature has been the inclusion of some form of physical activity into classroom lessons, a development which has been termed the "active classroom" and one which links movement in the classroom and "brain based" approaches to learning (Davidson, 2007; Fox et al., 2004). Although there is no universal definition for the term "active classroom" it can be construed to mean the use of movement in an educational environment, lesson or classroom setting. There is some evidence for the support for the inclusion of physical activity that has been termed "implicit learning" within classroom activities (Jensen, 2000, in Davidson, 2007) which states that the provision of planned activity should be incorporated into every hour of the learner's learning, and lasting for approximately ten minutes. It is proposed that this could help sustain the learner's learning. However it is emphasised that there is still a general lack of empirical evidence within the literature for the support of this integration of 
physical activities within classroom lessons (Davidson, 2007; Fox et al., 2004).

Thus the aim of this study is to provide evidence to support the promotion of the "active classroom" as a learning environment, as well as to demonstrate that providers of "active classroom" programmes don't necessarily have to come from traditional educational establishments, such as schools and colleges. There is now evidence for a wide diversity of educational providers developing and implementing educational programmes to schools and colleges across the UK. In many situations these "outside providers" are being brought into the school environment to provide the appropriate education as many educational establishments either do not have the resources or the skilled educators to deliver the appropriate material. The focus of this study will be based on the development and delivery of an "active classroom" experience by The Manchester United Foundation which is the charitable arm of Manchester United Football Club. The pilot programme in review is one which combines elements of enterprise learning and physical activity. Gibb (1993) and latterly Packham et al. (2010) have both suggested that enterprise education should just focus on not just those skills needed to create a new venture but should also be used to assist the development of the enterprising individual. The development of enterprise skills which forms part of the entrepreneurial process lends itself well to the integration of physical activities, as both physical education and entrepreneurship have been both associated with the development of skill sets such as self-efficacy (Ekeland et al., 2004).

\section{Research Methodology}

The research approach selected for this study, was a single case study approach. Smith (2012) states that a single case study approach refers "to the participant or cluster of participants (e.g., a classroom, hospital, or neighbourhood) under investigation". Typically this involves a comparison between differing "experimental time periods", which he states as phases. Smith (2012) goes on to mention that the central goal of the single case is to determine whether a causal or functional relationship exists between an independent variable and a meaningful change in the dependent variable. The use of single case study approach is an appropriate methodology for this study as the research aims to examine the processes, outcomes and behavioural interventions (Yin, 2011) through the delivery of an "active classroom" programme and provide evidence to assess its effectiveness.

\section{Case Study Manchester United Manchester United Foundation}

The Manchester United Foundation is the charitable arm of Manchester United Football Club with its roots stretching back to football in community sessions established in the early 1990's. The aim of the Foundation is to provide support for young people as well as to raise awareness of the importance for young people to make healthy lifestyle choices and develop into responsible citizens. The Manchester United Foundation delivers this support primarily through the 
power of the Manchester United brand which has the unique ability to reach out to young people (MU Foundation, 2011), which is reflected through its mission statement:

Goal: To educate, motivate, and inspire future generations to build better communities for all.

Mission: To channel the worldwide passion for Manchester United to influence positive change within communities by:

- Developing unique and relevant partnerships.

- Empowering young people through the delivery of innovative and educational programmes.

- Developing greater understanding of social issues through education.

Values: Responsible-Respect-Achievement-Excellence-Investment-Passion

Through the foundation, a wide range of educational opportunities are offered to young people living within the local Manchester area. The opportunities vary from educating youngsters about the inner workings of a football club to improving confidence, life-skills and employability skills. The programmes are innovative and inspiring, everything you would expect from a Premiership Club such as Manchester United (MU Foundation, 2012).

\section{The Manchester United Enterprise Academy}

The Manchester United Enterprise Academy (MUEA) is a branch of the Manchester United Foundation and is responsible for the delivery of a range of unique educational learning schemes that runs across a number of local schools all of which are aimed at educating pupils about business and enterprise and the wider issues of employability. Figure 1 below shows a visual representation of MUEA:

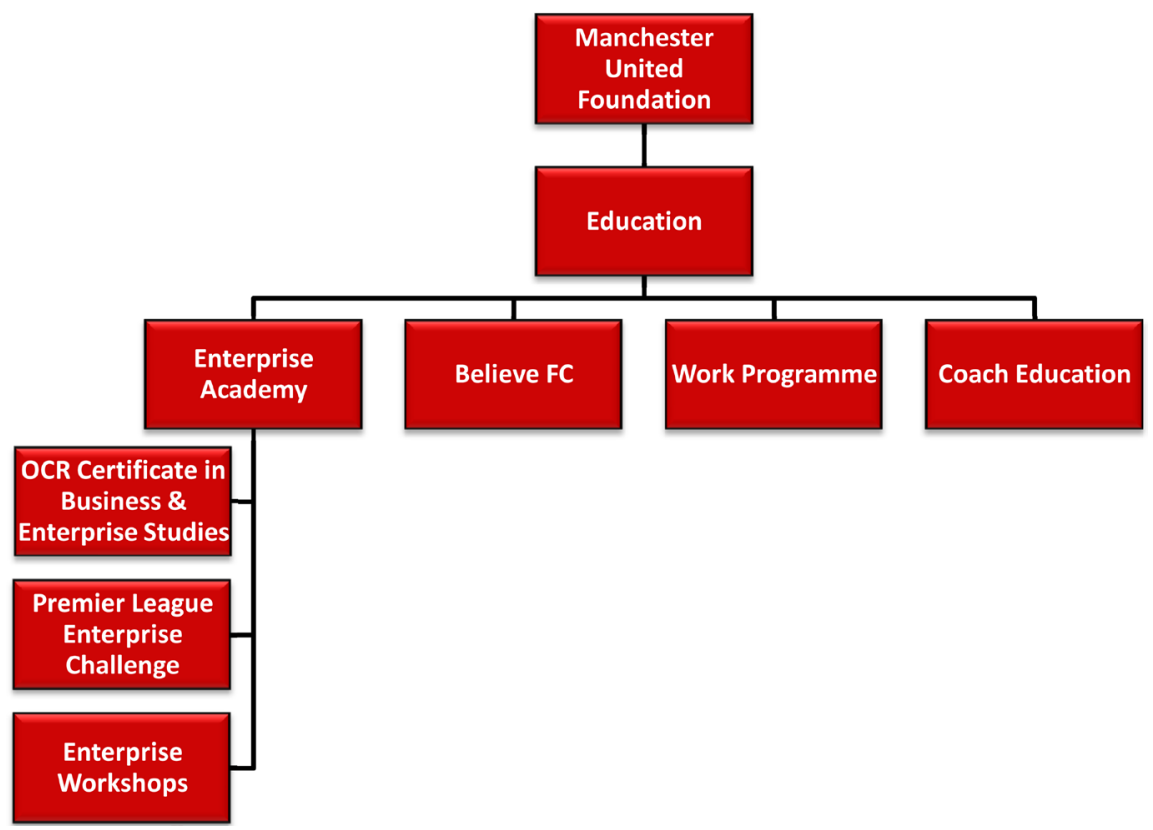

Figure 1. Overview of the MU Foundation structure (MU Foundation, 2012). 
The aims of the Manchester United Enterprise Academy (MUEA) are to:

- Give young people the skills and knowledge they will need to gain employment.

- Work with valuable partners who share the same ethos in education and community cohesion.

- Create a sustainable project by providing revenue streams.

Through the Manchester United Enterprise Academy educational programmes, pupils are given the opportunity to work towards and gain nationally recognised qualifications tailored to reflect the abilities and age range of the pupils undertaking the various programme. Typically the Manchester United Enterprise Academy works with young people from the ages 8 - 18 from school based around the club's local community. The educational programmes not only focus on the wider development of business skills but also allow young people to be educated on the inner workings of a Premier League football club, explaining that occupations within the club stem much further than the eleven players on the pitch. Each participating school receives a workbook and resources specifically created by the Manchester United Enterprise Academy, which introduces students to the basic principles of business through a range of interactive learning opportunities.

The courses delivered include:

- OCR Certificate in Employability Skills-Entry Level 3, Level 1 and Level 2.

- OCR National Certificate in Business \& Enterprise-Entry Level 3.

- Enterprise Events and Workshops-In school or at Old Trafford.

- Work Placements and Life Skills Mentorship.

This is not a unique phenomenon to Manchester United, as there are numerous other football clubs running similar programmes which focus on subjects which incorporate aspects of Business and Enterprise. However, MUEA have been deemed the club which has set the national benchmark in this area by designing their own personalised educational materials. The MUEA was also one of the first clubs to offer an employability based skills courses, all of the Manchester United Enterprise Academy educational programmes are OCR accredited.

\section{Data Collection Process}

The data for the active classroom pilot study was collected over a nine week period and came from a primary school in the local Manchester area that was participating in the enterprise programme. The study data was provided through the Manchester United Foundation as part of their course evaluations and subsequently all research will be presented and discussed anonymously. The study group consisted of 22 year 5 pupils of ages 9 - 10; who were participating on enterprise course. The course was developed around the concept of pupils in groups of 4 - 6 creating their own company and designing a new shirt for the Manchester United mascot Fred the Red. The 9 weeks course was delivered in two parts; the first part of the course was the enterprise challenge consisting of 
one hour lessons in the pupil's classrooms where pupils were given specific tasks based around:

- Creating a company.

- Market Research.

- Designing a football shirt.

- How your shirt makes money.

- Advertising a shirt through various mediums.

Each week the pupils work through tasks set out in their work booklets, created by the Manchester United Foundation. The aim of the course was to introduce the pupils to enterprise education using the power of the Manchester United Brand: to first engage the pupils with the topic, then inspire them to make them feel that they can succeed in whatever challenges that they may face and finally to educate them by giving them an insight into the world of enterprise and entrepreneurship. The classroom activity was then directly preceded by an hour of physical activities, where each of the 22 pupils were assessed against a range of Fundamental Motor Skills (FMS) comprising of 14 components based on those developed for the Move With Manchester United. The Move with Manchester United Programme focuses on pupils becoming competent and confident movers, i.e. more physically literate; the programme promotes fundamental movement skills which focus on the development of:

- Locomotion-movement from one point to another.

- Stability-body balance in static and dynamic movement situations.

- Objective control-sending receiving and controlling an object.

The pilot programme consisted of nine 1 hour sessions, with each session being broken down into a number of activities, one being a warm up activity followed by a main game activity. Prior to the start of the physical activity the children were given a verbal instruction and a single demonstration of each skill before attempting the activity. Each of the nine sessions focuses on a range of physical movements with the intention to specifically develop a pupil's agility, balance coordination and general body control. Each session allows a child to develop a specific set of skills that can determine the personal progress a child will make on its individual physical literacy journey (MU Foundation, 2016).

Over the nine weeks of the programme the 14 skills that were assessed were Balance, Hopping, Skipping, Jumping, Throw into a Hoop, Balance Bean Bag on Head, Throw and Catch, Bounce and Catch, Bowling, March in Ladders, Jump and Twist, Pass with inside of foot, Stand with one foot on the ball, Dribble. The 14 Fundamental Motor Skills were considered due to their relative simplicity and variety. Assessment of level of Mastery for each of the skill was carried out by the educator/coach who comparing the performance between the range of skills at the start and the end of the programme.

\section{Data Analysis}

Basic analysis of each of the 14Fundamental Motor Skills was recorded against each pupil, with an initial indication of the pupil's ability to either do the skill or 
not to do the skill and then whether the pupil could do it after intervention of the programme. The data presented is based on the level of the Mastery of the 14fundamental motor skills which is presented as a bar chart, Figure 2.

\section{Results}

Figure 2 reveals the pupil's success rates against their initial ability for the 14 Fundamental Motor Skills. The results show that there was an overall increase in the ability of the pupils to successfully Master 6 out of the 14 Fundamental Motor Skills after the intervention from the programme.

\section{Discussion}

As reported by Davidson (2007) the development and promotion of "active classrooms" is an area that educators and teachers alike could have a significant influence on, and one which could benefit both children's physical activity and mental health levels. This case study has set out to examine the delivery of a pilot "active classroom" programme created and delivered by the Manchester United

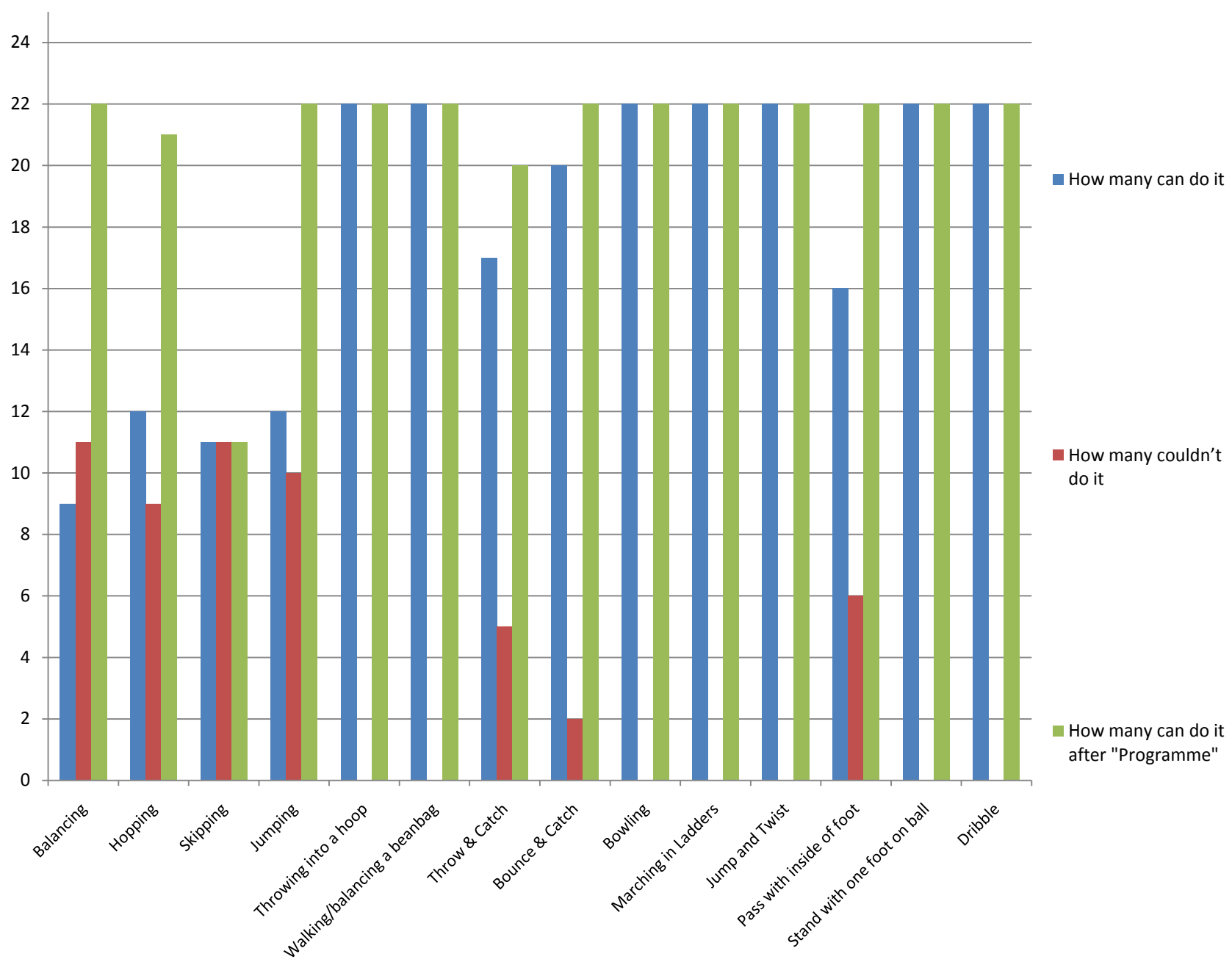

Figure 2. Shows the bar chart for the combined data for mastery levels of each of the 14 fundamental motor skills before and after the programme. 
Foundation. The educational content of the active classroom programme, focused on both the development of enterprise skills and 14 key Fundamental Motor Skills. Each of the 14 Fundamental Motor Skills: balancing, hopping, skipping, jumping, throwing into a hoop, walking/balancing a beanbag, throw \& catch, bounce \& catch, bowling, marching in ladders, jump and twist, pass with inside of foot, stand with one foot on ball, dribble has been identified by Manchester United as being vital to becoming physically literate (MU Foundation, 2016). Many of these 14 Fundamental Motor Skills have been highlighted within the literature (Griffiths \& Billard, 2013) as being Key Motor Skills indicators for children's educational and physical development Clark (2007) and thusmake them ideal for a point of comparison for this study. It should also be highlighted that the results presented in this study, only focus on the outcome of the delivery of the physical activity side of the programme and do not look at the effects on the development of the enterprise skills. Although a small representative sample size of 22 pupils was used, the results presented do throw up some interesting observations. Initial indication of the children's Mastery of the 14 Fundamental Motor Skills, showed that prior to the intervention of the programme some of the children showed initial signs of delay in their motor age, when comparing the Fundamental Motor Skills for similar aged children to that in the literature Griffiths and Billard (2013).

It can be seen Table 1 , that at the beginning of the programme that only $50 \%$

Table 1. Shows a breakdown of the percentages scores for each of the 14 fundamental motor skills before and after the intervention of the programme.

\begin{tabular}{|c|c|c|c|}
\hline $\begin{array}{c}\text { Beginners Level } \\
\text { Fundamental Motor } \\
\text { skills }\end{array}$ & $\begin{array}{c}\text { How many can } \\
\text { do it } \%\end{array}$ & $\begin{array}{c}\text { How many couldn't } \\
\text { do it } \%\end{array}$ & $\begin{array}{c}\text { How many can do it after } \\
\text { the Programme \% }\end{array}$ \\
\hline Balancing & 41 & 59 & 100 \\
\hline Hopping & 55 & 45 & 96 \\
\hline Skipping & 50 & 50 & 50 \\
\hline Jumping & 55 & 45 & 100 \\
\hline Throwing into a hoop & 100 & 0 & 100 \\
\hline $\begin{array}{c}\text { Walking/balancing a } \\
\text { beanbag }\end{array}$ & 100 & 0 & 100 \\
\hline Throw \& Catch & 77 & 23 & 91 \\
\hline Bounce \& Catch & 91 & 9 & 100 \\
\hline Bowling & 100 & 0 & 100 \\
\hline Marching in Ladders & 100 & 0 & 100 \\
\hline Jump and Twist & 100 & 0 & 100 \\
\hline Pass with inside of foot & 73 & 27 & 100 \\
\hline $\begin{array}{l}\text { Stand with one } \\
\text { foot on ball }\end{array}$ & 100 & 0 & 100 \\
\hline Dribble & 100 & 0 & 100 \\
\hline
\end{tabular}


of the children were able to carry out half of the 14 physical activities to complete Mastery the other $50 \%$ of the pupils had a combined average Mastery level of $36 \%$, with some children only having a proficiency Mastery percentage level of $9 \%$ in the Bounce \& Catch activity; which could be a sign of delayed performance of Fundamental Motor Skills in this group of children. As reported by (Braga, Krebs, Valentini, \& Tkac, 2009; Brauner \& Valentini, 2009) such delays could potentially lead to a reduced ability for skill acquisition in subsequent years. One possible explanation for this delay in object control skills is that children from this particular study may well have suffered from a lack of experience in performing manipulative tasks due to a lack of timetabled Physical Education (PE) in their curricular. Evidence already reported by (Pellegrini \& Bohn, 2005; Boyle et al., 2003) showed that children who do undertake regular physical activity improve many aspects of their motor and social skills than those who did not.

Influencing aspects in the Mastery of Fundamental Motor Skills can also be observed in these results. By the end of the 9 week programme, children undertaking the activities, delivered by specialist educational coach-teachers, showed an overall $50 \%$ increase in their ability to perform all 14 Fundamental Motor Skills than when they had initially started. It can also be reported that through the intervention of the programme, $79 \%$ of the children participating displayed complete Mastery of the 14 Fundamental Motor Skills. Again these results indicate that regular physical activity, provided by specialist educational teachers-coaches can have a beneficial influence that promotes development Fundamental Motor Skills; similar results having been identified in research carried out by (Braga, Krebs, Valentini, \& Tkac, 2009; Brauner \& Valentini, 2009; Lopes, Lopes, \& Pereira, 2004). These studies also demonstrated improvements in Fundamental Motor Skill performance due to specific intervention programmes however the results from this study show the effects due to physical education delivered in an "active classroom" programme. The results as highlighted in this study are important for a number of reasons. Firstly, it is important to demonstrate that external professional's organisation such as the Manchester United Foundation can developed ucationally robust programmes for educational institutions, such as schools and colleges. Also that through their innovative delivery methods children can demonstrate marked improvements in their Fundamental Motor Skills sets. Secondly, the development of "active classroom" approaches, as demonstrated in this pilot study, could be seen as an appropriate option for some educational institutions. This is because regular physical activities would be provided through this "active classroom" environment thus providing the appropriate stimulus and necessary practice to promote development of Key Functional Motor Skills; thus reducing the need for children to be enrolled on specific Physical Activity programmes to supplement the development of Key Motor Skills. However it should be stated that the use of "active classrooms" should not be seen as an alternative to the provision of regular Physical Education (PE) as reported by Fairclough \& Stratton (2005); Fairclough et al. (2002); Gard \& Wright (2001); WHO (1998). 


\section{Conclusion}

The presented case study examines the delivery of a pilot study of an "active classroom" to 22 years 5 pupils by Manchester United Foundation. The case study provides an interesting insight into an area of physical educational development that has received little attention within the literature.

Results of the physical activities developed as part of the "active classroom" programme do seem to show that through the delivery of the programme, pupils who were weak in some specific Fundamental Motor Skills such as Balancing, Hopping, Skipping, Jumping, Throw \& Catch, Bounce \& Catch, Pass with inside of foot showed a significant increase in their ability to carry out the activity. The integration of physical activity into classroom lessons and the notion of the "active classroom" is a particular area that teachers could have a significant influence on and potentially impact on the physical activity levels of children. This is important for educationalist and policy makers to know when making the decisions of what to provide in the way of the best resources for children's development as they progress through their education life cycle.

It is, however, important to point out the limitations of this study. The data set presented is only very small, 22 children. It would have also been of interest to have gained a better insight and more specific data on the pupil's profiles. However this does provide an opportunity for academics in the field to conduct further work on the promotion of "active classrooms". Future studies could look at larger samples of children; with better defined pupil profiles such as male to female ratios. It would also to gain an understanding of those children that participate in physical activities outside of the educational environment, as this may have provided them with added advantages. This said we feel that this study does bring some valuable insights to the field of educational development.

\section{Acknowledgements}

We would like to acknowledge the help and support of the Manchester United Foundation in the development of this paper.

\section{References}

Andersen, L. B., Harro, M., Sardinha, L. B., Froberg, K., Ekelund, U., Brage, S., \& Andersen, S. A. (2006). Physical Activity and Clustered Cardiovascular Risk in Children: A Cross-Sectional Study (The European Youth Heart Study). The Lancet, 368, 299-304. https://doi.org/10.1016/S0140-6736(06)69075-2

Boyle, D. E., Marshall, N. L., \& Robeson, W. W. (2003). Gender at Play: Fourth-Grade Girls and Boys on the Playground. American Journal of Health Behaviour, 46, 13261345. https://doi.org/10.1177/0002764203046010004

Braga, R. K., Krebs, R. J., Valentini, N. C., \& Tkac, C. M. (2009). Ainfluência de um programa de intervençãomotora no desempenho das habilidadeslocomotoras de crianças com idade entre 6 e 7 anos. Revista da Educação Física/UEM, 20, 171-181.

Brauner, L. M., \& Valentini, N. C. (2009). Análise do desempenho motor de criançasparticipantes de um programa de atividadesfísicas. Revista da Educação Física/UEM, 20, 205-216. 
Cale, L. (1997). Promoting Physical Activity through the Active School. British Journal of Physical Education, 28, 19-21.

Clark, J. E. (2007). On the Problem of Motor Skill Development. Journal of Physical Education, Recreation \& Dance, 78, 39-44. https://doi.org/10.1080/07303084.2007.10598023

Davidson, F. (2007). Childhood Obesity Prevention and Physical Activity in Schools. Health Education, 107, 377-395.

Ekeland, E., Heian, F., Hagen, K. B., Abbott, J., \& Nordheim, L. (2004). Exercise to Improve Self-Esteem in Children and Young People. Cochrane Database Systematic Reviews, No. 1, Article No. CD003683. https://doi.org/10.1002/14651858.cd003683.pub2

Fairclough, S., \& Stratton, G. (2005). "Physical Education Makes You Fit and Healthy". Physical Education's Contribution to Young People's Physical Activity Levels. Health Education Research, 20, 14-23. https://doi.org/10.1093/her/cyg101

Fairclough, S., Stratton, G., \& Baldwin, G. (2002). The Contribution of Secondary School Physical Education to Lifetime Physical Activity. European Physical Education Review, 8, 69-84. https://doi.org/10.1177/1356336X020081005

Fiscella, K., \& Kitzman, H. (2009). Disparities in Academic Achievement and Health: The Intersection of Child Education and Health Policy. Pediatrics, 123, 1073-1080. https://doi.org/10.1542/peds.2008-0533

Fox, K. R. (2004). Tackling Obesity in Children through Physical Activity: A Perspective from the United Kingdom. Quest, 56, 28-40. https://doi.org/10.1080/00336297.2004.10491813

Gard, M., \& Wright, J. (2001). Managing Uncertainty: Obesity Discourses and Physical Education in a Risk Society. Studies in Philosophy and Education, 20, 535-549. https://doi.org/10.1023/A:1012238617836

Gibb, A. A. (1993). The Enterprise Culture and Education: Understanding Enterprise Education and Its Links with Small Business, Entrepreneurship and Wider Educational Goals. International Small Business Journal, 11, 11-34. https://doi.org/10.1177/026624269301100301

Griffiths, G., \& Billard, R. (2013). The Fundamental Movement Skills of a Year 9 Group and a Gifted and Talented Cohort. Advances in Physical Education, 3, 215-220.

Gu, X. L., \& Zhang, T. (2016). Changes of Children's Motivation in Physical Education and Physical Activity: A Longitudinal Perspective. Advances in Physical Education, 6, 205-212. https://doi.org/10.4236/ape.2016.63022

Janak, J. C., Gabriel, K. P., Oluyomi, A. O., Peréz, A., Kohl, H. W., \& Kelder, S. H. (2014). The Association between Physical Fitness and Academic Achievement in Texas State House Legislative Districts: An Ecologic Study. Journal of School Health, 84, 533-542. https://doi.org/10.1111/josh.12176

Janssen, I., Katzmarzyk, P. T., Boyce, W. F., Vereecken, C., Mulvihill, C., Roberts, C., Currie, C., \& Pickett, W. (2005). Comparison of Overweight and Obesity Prevalence in School-Aged Youth from 34 Countries and Their Relationships with Physical Activity and Dietary Patterns. Obesity Reviews, 6, 123-132. https://doi.org/10.1111/j.1467-789X.2005.00176.x

Kremers, S. P. J., De Bruijn, G. J., Visscher, T. L. S., Van Mechelen, W., De Vries, N. K., \& Brug, J. (2006). Environmental Influences on Energy Balance-Related Behaviors: A Dual Process View. International Journal of Behavioral Nutrition and Physical Activity, 3, 9. https://doi.org/10.1186/1479-5868-3-9

Kristjánsson, A. L., Sigfúsdóttir, I. D., \& Allegrante, J. P. (2010). Relative Contribution of Dietary Habits, Physical Activity, Body Mass Index, Health Behavior and Academic 
Achievement among Adolescents. Health Education and Behavior, 37, 51-64. https://doi.org/10.1177/1090198107313481

Lopes, L., Lopes, V. P., \& Pereira, B. (2004). Atividadefísica no recreio escolar: Estudo de intervençãoemcrianças dos seisaos 12 anos. Revista Brasileira de Educação Física e Esporte, 20, 271-280.

MU Foundation (2011). Football in the Community.

MU Foundation (2012). Football in the Community.

MU Foundation (2016). Move With Manchester United.

Pellegrini, A. D., \& Bohn, C. M. (2005). The Role of Recess in Children's Cognitive Performance and School Adjustment. Educational Research, 34, 13-19. https://doi.org/10.3102/0013189X034001013

Shephard, R. J., \& Lavallee, H. (1994). Impact of Enhanced Physical Education on Muscle Strength in the Prepubescent Child. Pediatric Exercise Science, 6, 75-87. https://doi.org/10.1123/pes.6.1.75

Smith, J. D. (2012). Single-Case Experimental Designs: A Systematic Review of Published Research and Current Standards. Psychological Methods, 17, 510-550. https://doi.org/10.1037/a0029312

Snelling, A., Belson, S. I., Beard, J., \& Young, K. (2014). Associations between Grades and Physical Activity and Food Choices: Results from YRBS from a Large Urban School District. Health Education, 115, 141-151.

Tomporowski, P. D., Davis, C. L., Miller, P. H., \& Naglieri, J. A. (2008). Exercise and Children's Intelligence, Cognition, and Academic Achievement. Educational Psychology Review, 20, 111-131. https://doi.org/10.1007/s10648-007-9057-0

World Health Organization (WHO) (1998). The WHO Approach to Health Promotion Settings for Health. Geneva: WHO.

Yin, R. K. (2011). Application of Case Study Research (3rd ed.). Thousand Oaks, CA: Sage.

Scientific Research Publishing

Submit or recommend next manuscript to SCIRP and we will provide best service for you:

Accepting pre-submission inquiries through Email, Facebook, LinkedIn, Twitter, etc. A wide selection of journals (inclusive of 9 subjects, more than 200 journals)

Providing 24-hour high-quality service

User-friendly online submission system

Fair and swift peer-review system

Efficient typesetting and proofreading procedure

Display of the result of downloads and visits, as well as the number of cited articles

Maximum dissemination of your research work

Submit your manuscript at: http://papersubmission.scirp.org/

Or contact ape@scirp.org 